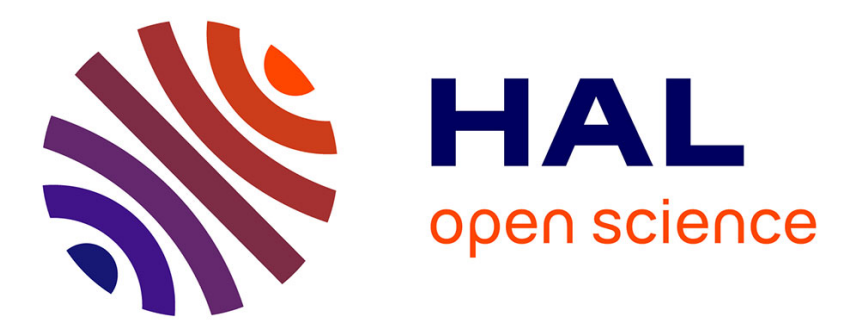

\title{
Player-video game interaction: A systematic review of current concepts
}

\author{
Loïc Caroux, Katherine Isbister, Ludovic Le Bigot, Nicolas Vibert
}

\section{To cite this version:}

Loïc Caroux, Katherine Isbister, Ludovic Le Bigot, Nicolas Vibert. Player-video game interaction: A systematic review of current concepts. Computers in Human Behavior, 2015, 48, pp.366-381. 10.1016/j.chb.2015.01.066 . hal-01108083

\section{HAL Id: hal-01108083 \\ https://hal.inria.fr/hal-01108083}

Submitted on 22 Jan 2015

HAL is a multi-disciplinary open access archive for the deposit and dissemination of scientific research documents, whether they are published or not. The documents may come from teaching and research institutions in France or abroad, or from public or private research centers.
L'archive ouverte pluridisciplinaire HAL, est destinée au dépôt et à la diffusion de documents scientifiques de niveau recherche, publiés ou non, émanant des établissements d'enseignement et de recherche français ou étrangers, des laboratoires publics ou privés. 


\section{PRE PRINT}

Caroux, L., Isbister, K., Le Bigot, L., \& Vibert, N. (in press). Player-video game interaction: a systematic review of current concepts. Computers in Human Behavior.

NOTICE: this is the author's version of a work that was accepted for publication in "Computers in Human Behavior". Changes resulting from the publishing process, such as peer review, editing, corrections, structural formatting, and other quality control mechanisms may not be reflected in this document. Changes may have been made to this work since it was submitted for publication. The definitive version will appear in "Computers in Human Behavior".

Running head: Player-video game interaction

Title:

Player-video game interaction: a systematic review of current concepts

Authors:

Loïc Caroux ${ }^{\text {ab1 }}$, Katherine Isbister ${ }^{\mathrm{a}}$, Ludovic Le Bigot ${ }^{\mathrm{b} 2}$, and Nicolas Vibert ${ }^{\mathrm{b}}$

Affiliations:

${ }^{a}$ Game Innovation Lab, New York University, 5 Metrotech Center, Brooklyn, NY 11201, USA

${ }^{b}$ Centre de Recherches sur la Cognition et l'Apprentissage, UMR 7295 Université de Poitiers - Université de Tours - CNRS, 5 rue Théodore Lefebvre, TSA 21103, 86073 Poitiers Cedex 9, France

E-mail addresses:

loic.caroux@inria.fr; katherine.isbister@nyu.edu; ludovic.le.bigot@univ-poitiers.fr; nicolas.vibert@univ-poitiers.fr

Corresponding author:

Loïc Caroux

Inria Bordeaux Sud-Ouest

200 avenue de la vieille tour

33405 Talence Cedex

France

E-mail: loic.caroux@inria.fr

\footnotetext{
${ }^{1}$ Present affiliation: Inria Bordeaux Sud-Ouest, 200 avenue de la vieille tour, 33405 Talence Cedex, France

${ }^{2}$ First name : Ludovic ; Last name : Le Bigot (double name)
} 


\section{Abstract}

Video game design requires a user-centered approach to ensure that the experience enjoyed by players is as good as possible. However, the nature of player-video game interactions has not as yet been clearly defined in the scientific literature. The purpose of the present study was to provide a systematic review of empirical evidences of the current concepts of player-video game interactions in entertainment situations. A total of 72 articles published in scientific journals that deal with human-computer interaction met the criteria for inclusion in the present review. Major findings of these articles were presented in a narrative synthesis. Results showed that player-video game interactions could be defined with multiple concepts that are closely linked and intertwined. These concepts concern player aspects of player-video game interactions, namely engagement and enjoyment, and video game aspects, namely information input/output techniques, game contents and multiplayer games. Global approaches, such as playability, also exist to qualify player-video game interactions. Limitations of these findings are discussed to help researchers to plan future advances of the field and provide supplementary effort to better know the role of less-studied aspects. Practical implications are also discussed to help game designers to optimize the design of player-video game interactions.

\section{Keywords}

Digital game; Entertainment; Engagement; Enjoyment; Playability; Player experience. 


\section{Highlights}

- The nature of player-video game interactions is not clearly defined in the literature

- The review showed that several concepts are relevant to qualify these interactions

- Player aspects such as engagement and enjoyment are relevant

- Video game aspects as input/output, game contents and multiplayer are relevant

- Global approaches such as playability are also relevant. 


\section{INTRODUCTION}

Video games now constitute one of the world's premier cultural industries with a global market of 80 billion dollars in 2011 (Interactive Software Federation of Europe, 2011). Since the initial commercial success of the game "Pong" in 1972, video games have been experienced by many different categories of players on a wide range of different platforms. $48 \%$ of European adults aged 16 or more and $58 \%$ of Americans said that they had played video games in $2012,55 \%$ of these being men and $45 \%$ women (Entertainment Software Association, 2013; Interactive Software Federation of Europe, 2012). 68\% of American players played on game consoles, $63 \%$ on computers, $43 \%$ on smartphones, $37 \%$ on dedicated handled systems and 30\% on wireless devices (Entertainment Software Association, 2013).

The increasingly widespread popularity of video games has prompted the emergence of numerous scientific publications dealing with player-video game interactions and their implications for practical application. However, most of these publications continue to focus on the impact of games on the external behavior of players. In particular, some studies have examined the negative influence of violent video games on behavior (e.g., Anderson et al., 2010). Other researchers has emphasized the positive effects of cognitive training following interaction with action games (e.g., Bavelier, Green, Pouget, \& Schrater, 2012).

More recently, another community of researchers has published results not on the effect of video games on their players but on the nature of the player-game interaction itself, based on an examination of the players' motivations (e.g., search for pleasure, entertainment, challenges, emotions) (Barr, Noble, \& Biddle, 2007). Such studies help minimize disruptions to the interaction between the player and the game and thus ensure that the experience enjoyed by players is as good as it possibly can be. Playercentered studies of player-video games interactions are therefore of vital importance, in particular 
because they enable designers to create video games that can adapt to the expectations and capabilities of the users (Pagulayan et al., 2012).

The study of player-video game interactions remains difficult because they are hard to define (Pagulayan et al., 2012). The one characteristic common to all video games is the ability of the player to interact with a virtual environment, generally with the help of an artifact (e.g., joystick, movement detection sensor, touchscreen control). The main interface of this environment is presented in audio-visual form via a terminal, which is either specific (e.g., portable games console) or not specific to video games (e.g. television, smartphone, tactile tablet). This environment reacts to the orders received from the player and then sends new information via the interface. Unlike other media that convey audio-visual information, such as the cinema for example, video games enable users to interact with this information. This player-video game interaction is clearly the key point that differentiates games from other types of cultural media.

The purpose of the present article was to provide a systematic review of empirical evidence of the current concepts of player-video game interactions as described in scientific journals. The aim was to show that, in terms of human-computer interactions, video games should be considered above all as complex IT systems, with which individuals wish to interact within the framework of a goal-directed activity.

The goals of video game players when using video games are very diverse. Although nowadays, video games can be used, for example, in education (e.g., Connolly, Boyle, MacArthur, Hainey, \& Boyle, 2012; Egenfeldt-Nielsen, 2006), or work activities (e.g., E. Boyle, Kennedy, Traynor, \& Hill, 2011), the original aim of video games was to entertain the player. So, to be as generally applicable as possible, the purpose of the present article was to provide a systematic review of empirical evidences of the current concepts of player-video game interactions in entertainment situations only. 


\section{METHOD}

\subsection{Search database}

This literature search method was configured to target empirical evidence focused only on the intrinsic concepts of the player-video game interaction in entertainment situations. This excluded studies about serious games, educational games, game culture, the nature of the games, the nature of players, and the effects of using a game on human behavior or the use of games as research tool or for other activities than entertainment. To reach this goal as precisely as possible, only main scientific journals that deal with human-computer interaction $(\mathrm{HCl})$ were used in the search database. These journals were those that were indexed in the journal list of $\mathrm{HCl}$ Bibliography ${ }^{3}$ database (hosted by ACM SIGCHI) in 2013. This list was supplemented by journals indexed in the Science Citation Index Expanded and the Social Sciences

Citation Index (Thomson Reuters) categorized in the "Computer Science, Cybernetics" ${ }^{4}$ or "Ergonomics" 5 subject categories in 2013. The journals included in the search database are listed in the Appendix.

\subsection{Selection criteria for inclusion of papers in the current review}

To avoid missing articles that would use different terms than video games to qualify them (e.g., computer games, digital games), the only search term was "game" in abstract, title or keywords (if available). The search was run in all journal volumes published from their beginning (1933 for the oldest) to 2013 included. A total of 1,270 articles were found. This selection was then narrowed by focusing on articles that included empirical evidence relating to player-video game interactions in entertainment situations with the constraints described above. To do so, each abstract was reviewed to detect the compatibility between the article and the criteria for inclusion. This review was done by the first author of the present article. The review process was as strict and objective as possible. The reviewer selected

\footnotetext{
${ }^{3}$ http://www.hcibib.org/show.cgi?file=journal, retrieved October 22nd, 2013

${ }^{4}$ http://science.thomsonreuters.com/cgi-bin/jrnlst/jlresults.cgi?PC=D\&SC=ER, retrieved October $22^{\text {nd }}, 2013$

${ }^{5}$ http://science.thomsonreuters.com/cgi-bin/jrnlst/jlresults.cgi?PC=SS\&SC=Jl, retrieved October $22^{\text {nd }}, 2013$
} 
only the papers that focused on interaction between video/computer/digital/electronic games and players in entertainment situations and that contained an empirical study. When the abstract was ambiguous, the whole text was screened. A total of 72 articles met the criteria for inclusion in the current review. They were published from 2000 to 2013 included. Then, these papers were analyzed according to their main goal of study, research design and method, and major findings. The design of each study was categorized according to whether it used an experimental design (including controlled or single-subject experiments), a survey, a qualitative design or a case study. 


\section{RESULTS}

The analysis of the seventy-two papers showed that their main goals of study, research designs and methods were very diverse. To capture this heterogeneity of topics and approaches, a narrative synthesis was adopted. Thus, the present section was divided into six sections according to the main goal of each paper. The majority of the articles studied specific aspects of the player-video game interaction (Figure 1). Sections 3.1 and 3.2 introduce the player (human) aspects of the player-video game interaction. Player aspects studied in the literature concern the experience that a person has or looks for during interaction with video games, namely engagement and enjoyment. Engagement primarily includes "immersion" and "presence". Enjoyment is linked to concepts of flow and emotions. Sections 3.3, 3.4 and 3.5 introduce the video game (computer) aspects of the player-video game interaction. Video game aspects concern the technical aspects of the player-video game interaction, which are designed by game designers. The three main aspects studied in the literature are the techniques of information input (e.g., motion-based control) and output (e.g., visual display), game contents (e.g., challenge and narration) and multiplayer games. The other segment of the articles studied player-video game interaction from a holistic perspective, examining concepts such as playability or game values. These are presented in the section 3.6.

[Insert Figure 1 near here]

Each section of the results is structured in the same way. First, each concept used in the literature is briefly introduced. Then, a more detailed definition of each concept is given and the corresponding empirical evidence is presented. The empirical evidences of influence of a video game concept on a 
player concept (e.g., game contents on player's engagement) are detailed in the video game concept corresponding section (i.e. section $3.3,3.4$ or 3.5).

\subsection{Player engagement: immersion, presence and perceived realism}

The literature review showed that players may have experiences, which can be conceptualized in ways that have relevance to other $\mathrm{HCl}$ contexts. These include (1) engagement, (2) immersion, (3) presence, and (4) perceived realism. Several papers studied these constructs from the specific point of view of player-video game interactions and showed that player experiences are closely linked to those in other $\mathrm{HCl}$ contexts. Five papers used survey methodology. One paper used an experimental study, and another is based on a case study.

First, engagement is related to the level of motivation displayed by the user of a video game and includes immersion, and presence or perceived realism (see E. A. Boyle, Connolly, Hainey, \& Boyle, 2012 for a specific review). Engagement is defined as a "high degree of involvement in computer usage" (Charlton \& Danforth, 2007, 2010). One issue with this concept, according to Charlton and Danforth, is that computing-related engagement (non-pathological behavior) is near to the concept of computing-related addiction, which is a pathological behavior. In two survey papers, these authors studied the distinction between these two concepts in video gaming. They showed that addictive play behavior is significantly correlated with personality variables (e.g., high extraversion and low emotional stability positively correlated with high addiction), but not engagement. Second, immersion is defined as "a psychological state characterized by perceiving one's self to be enveloped by, included in, and interacting with an environment that provides a continuous stream of stimuli and experiences" (Stanney \& Salvendy, 1998; Witmer \& Singer, 1998). Third, presence is defined as "the subjective experience of being in one place or environment even when one is physically located in another" (Stanney \& Salvendy, 1998). Presence can be divided into three dimensions: spatial presence (linked to the virtual or distant objects), social 
presence (linked to the virtual or distant social actors) and self-presence (linked to the virtual or represented self) (K. M. Lee, 2004). Presence is the concept that has received the most attention in connection with the study of video games. The concept is particularly well adapted for these environments because it relates to a state of perceptual illusion, in which the barrier between the real and virtual worlds ceases to exist (Draper, Kaber, \& Usher, 1998; K. M. Lee, 2004; Stanney \& Salvendy, 1998). Fourth, perceived realism refers to the subjective realism of the virtual world that users feel (Malliet, 2006). Two survey studies investigated more precisely perceived realism in player-video game interactions. Ribbens and Malliet (2010) showed that several factors from the virtual world constitute perceived video game realism: the realism of the simulation, freedom of choice, character involvement, perceptual pervasiveness, authenticity regarding subject matter, and authenticity regarding characters and social realism. In addition, Bae et al. (2012) showed that the player's egocentric (perception of selflocation in the environment and its manipulation) and global (perception of fullness of objects and their manipulation) representations of the virtual world positively influence perceived realism.

Three papers focused on methods to measure player engagement in video games. In a survey study, Qin, Rau, and Salvendy (2009) proposed an immersion questionnaire based on game narrative factors. The authors evaluated and validated a questionnaire based on seven factors: the "curiosity" of the player to explore the game narrative, "concentration", "comprehension", "empathy", "familiarity", and "challenge" of a game's narrative and corresponding player "skills", and the "control" proposed by the game narrative. Similarly, Retaux (2003) proposed the auto-confrontation method to evaluate the variations of presence during a game session, and validated it with a case study. The principle of this method is to video record a game session and replay it while the player indicates his or her experience of presence. More objective and real-time methods have been validated, in particular for immersion. In an experimental study, Jennett et al. (2008) proposed the recording of eye movements which could reflect the player's level of immersion. The authors showed that a task that promotes the player's immersion in 
a video game is characterized by a reduction in the number of eye fixations and an increase in their duration over time. According to these authors, immersive tasks help keep the player's attention focused on the important elements of the task, whereas non-immersive tasks increase the player's visual distractibility.

Several papers showed that players' engagement in player-video game interaction can be influenced by different video games characteristics. The findings of these studies are detailed in the following corresponding sections of the present review (Sections 3.3, 3.4, and 3.5).

In summary, literature showed that engagement may be experienced by players during game play. Engagement is related to the level of motivation displayed to the user of a video game. It must not be confused with addiction, which is a pathological behavior. Engagement in video games includes immersion, presence and perceived realism, which are also experienced by individuals in other contexts of $\mathrm{HCl}$, typically when virtual environments are displayed. Several methods were proposed and validated to measure immersion (questionnaire, eye-tracking) or presence (auto-confrontation).

Engagement is one characteristic that player-video game interactions share with other $\mathrm{HCl}$ contexts. However, video games are also objects of entertainment. According to the literature, at least one further specific parameter can be used to characterize the interaction between a player and a video game: enjoyment.

\subsection{Player enjoyment, flow and emotions}

Literature review showed that, as in all entertainment activities, players may experience enjoyment, which is a positive player reaction during a gameplay session. The literature showed that flow could also be used to qualify the positive experience of players during game play. Enjoyment is generally linked to emotions (e.g., fun, boredom, excitement) felt by the player. Four papers used survey methodology to 
investigate enjoyment and flow in video games. One paper took an experiment-based approach to studying emotions.

Fang, Chan, Brzezinski, and Nair (2010) studied enjoyment, which they equated with positive player reactions during a gameplay session. They designed and validated a questionnaire based on three dimensions of enjoyment: affective (linked to players' emotions and affective states), cognitive (linked to players' judgments of elements of games) and behavioral (linked to players' behavior during game sessions). Flow is a euphoric state of concentration and involvement, often claimed to be one the most enjoyable and valuable experiences one can have (Csikszentmihalyi, 1990). Procci, Singer, Levy, and Bowers (2012) investigated a common scale to measure flow in video games: the Dispositional Flow Scale-2 (DFS-2) usually used to measure the tendency to experience flow in athletes. The authors showed that this scale was not a good fit for measuring the flow experience in the gamer population, in contrast with previous studies (e.g., Wang, Liu, \& Khoo, 2009). More recently, Fang, Zhang, and Chan (2013) designed and validated a specific questionnaire to measure flow in video games based on the different components of flow proposed by Csikszentmihalyi (1993).

Mandryk and Atkins (2007) have proposed a method for quantifying the emotional experience of an individual interacting with entertainment technologies such as video games. These authors used physiological measures to determine the real-time emotional state of individuals along two dimensions: mental arousal (from torpor to maximum arousal) and emotional valence (from unpleasant to pleasant feelings). The emotional state was estimated using measures of galvanic skin response, heart activity, smiling activity (electromyography) and frowning activity (electromyography). Based on an analysis of the positions of the emotional states of individuals on these two dimensions, the authors asserted that it is possible to identify five types of distinct sensation during a gameplay session: boredom, challenge, 
excitement, frustration and fun. For example, a player might experience a high level of frustration if his level of mental arousal was high at the same time as he was feeling negative emotions.

Several papers showed that players' enjoyment, flow and emotions can be influenced by different video games qualities. The findings of these studies are detailed in the following corresponding sections of the present review (Sections 3.3, 3.4, and 3.5).

In summary, literature showed that players may experience enjoyment when they play video games. Enjoyment is related to positive player reactions during a gameplay session, and is linked to emotional experience. Measuring physiological activity was validated to quantify the emotional experience of players in terms of mental arousal and emotional valence. Flow is also a concept used to qualify the positive experience of players. However, this concept was designed and studied outside the scope of video gaming. Therefore, classic tools to measure experience of flow in more general situations, such as the DFS-2, may not be applicable for video gaming situations. In contrast, a specific questionnaire to measure flow in video games was recently validated.

A major part of the articles included in this review studied specific sub-aspects of player-video game interaction. The studies presented in these two first sections of results concern player aspects of playervideo game interaction, such as engagement and enjoyment. The two following sections concern the video game aspects of player-video game interaction, such as information input/output, game contents and multiplayer games.

\subsection{Input and output characteristics of video game interfaces}

Two elements need to be taken into account when describing the interface of a video game: on the one hand, the way in which individuals can interact with this environment (information input) and, on the other, information provided by the interface that enables the user to interact with it (information output). Though there are existing rules in human-computer interface design (e.g., Nielsen, 1993), user 
interface designers in video games should not necessarily follow these rules. In a qualitative study, Johnson and Wiles (2003) showed that game designers have to violate these heuristics to design effective user interfaces in games. For example, player feelings of flow tend to be higher if less information is displayed on the screen, or if a only a few controller buttons are required to take multiple actions in the game. The present section presents specific studies on output and input information in video games.

\subsubsection{Output techniques: visual and auditory information}

According to the reviewed papers, information output in video games is composed of visual and auditory information. Typically, the visual interfaces of video games generally consist of a main action scene containing objects with which the player can interact (e.g. avatars, enemies or targets) and a complex, moving background (e.g. interiors, landscapes). A "heads-up display" is often superimposed on the main action scene to provide contextual information. In addition, auditory information is used to reinforce or facilitate the player-game interaction. Most of the papers of this section (11) used experimental studies. Only one paper described a case study.

Two experimental papers showed that some characteristics of visual backgrounds influence players' performance. Wolfson and Case (2000) hypothesized that the performance and mental arousal (measured by heart rate) would be influenced by the color (red or blue) of the background. The results showed that the scores and heart rates increased gradually throughout the game when a blue background was used. The use of a red background caused the scores and heart rates to increase faster than in the case of a blue background and then to fall off in the second half of the game. Red therefore resulted in faster arousal, but a habituation effect then reduced this arousal level. Whatever the color of the screen background, performance was correlated with the level of mental arousal. Caroux, Le Bigot, and Vibert (2013) investigated the influence of the overall motion of visual backgrounds in simple video games. The authors showed that a laterally moving background impaired players' performance, in 
comparison with a stationary one, when the game task is simple in terms of attentional demand. However, the authors also showed that there was no difference of performance between a radially moving or stationary background, whatever the game task difficulty.

The effects of the arrangement of contextual elements (e.g., head-up display) in the visual interfaces of video games have been studied in two experimental studies. Caroux, Le Bigot, and Vibert (2011) recorded eye movements to study the influence of the screen position of important context information (the score) on players' performances in a game requiring the visual anticipation of moving objects. They showed that positioning the score close to the area in which the objects were expected to move facilitated the anticipation of movements and the integration of all the information that is of use to the player. But, the performance of the players was better when the score was positioned just outside rather than even partially superimposed on the area of anticipation. Similarly, Sabri, Ball, Fabian, Bhatia, and North (2007) have shown that in the interfaces of high-resolution video games, the important context information that is most frequently consulted or used should be as close as possible to the cursor controlled by the player. In multi-monitor configurations, players have been found to perform their best when the context information is displayed on the monitor that is actually used.

The representation of the virtual world on the screen can be displayed in many ways. In an experimental study, Yannakakis, Martínez, and Jhala (2010) investigated the impact of camera point of view in three dimensional video games on player affect. Several points of view from combinations of distance, height and frame-to-frame transition were manipulated. Results showed that physiological measures varied depending upon point of view, and this correlated with the subjective measures. For example, low frame-to-frame transition and lower camera height increased frustration. Another example is that higher distance and height combined with fast frame-to-frame transition contributed positively to higher relaxation. In another experimental study, Parés and Altimira (2013) examined this question in the case 
of virtual reality games, in which whole body movement is needed to interact with the game. They showed that players judged the third-person view more positively, where the player's body was represented on the screen, in terms of sense of control, than the first-person view, where the player was not represented in any form. The authors also showed that players were more physically active with the third-person view. However, these differences were observed only when the game required use of the players' arms and legs. Finally, McCall and Braun (2008) studied an augmented reality system that does not use a simple screen to display visual information. Virtual information is projected on a headmounted display, and superimposed on real information that is actually the external background surrounding the player. In a case study, the authors showed that this kind of device could work in video game activities. However they found that the players could have problems switching their attentional focus between the virtual and real information.

Only one experimental study has investigated the influence of auditory information on game experience. Nacke, Grimshaw, and Lindley (2010) manipulated the presence of sound and music during an FPS play session. Subjective measures of game experience, including flow and tension, showed that sound is more important than music for the game experience. Generally sound contains elements of feedback that are an important part of user experience. However, these manipulations had no effect on players' physiological activity.

Finally, the quality of displayed information has been investigated in four experimental studies. Beyond information itself, the quality of information display also has an impact on player-video game interaction. Bracken and Skalski (2009) showed that image quality has influence on immersion in video games. The authors showed that players felt more immersion with high image quality (high definition TV) than low image quality (standard definition TV). Interestingly, spatial presence was not influenced. The authors suggested that spatial presence would be, in fact, influenced by other types of technology 
systems, such as virtual reality systems. Size of game screen also influences players' immersion. Hou, Nam, Peng, and Lee (2012) showed that playing on a large screen (such as a video projector screen) increased the impression of immersion. However, this did not significantly influence the subjective evaluation of the game in terms of interest, originality, graphical quality or the intention to recommend the game to others. Another indicator of image quality, frame rate, was also studied. Frame rate is a technical parameter of visual information updating on the screen. Claypool and Claypool (2007) showed that, with first person shooter games, the higher the frame rate was, the better players' performance was, and the higher the perceived quality of the image and perceived playability of the game were. Sound quality has also an impact on player-video game interactions. Skalski and Whitbred (2010) showed that players' presence and enjoyment were higher with high quality sound (5.1 surround sound) than low quality (stereo sound).

These studies have shown that the way visual and auditory information is presented, namely characteristics of background, contextual information, representation of virtual world, music and sound, and quality of displayed information, influences player performances as well as player experience. The next section examines information input techniques that also contribute to the experience of the player.

\subsubsection{Input techniques: Motion, tactile, tangibles, gaze and brain control}

The classic information input techniques in player-video game interaction are a controller with buttons to press and joysticks to rotate, or a computer keyboard and mouse combination. Nevertheless, new devices have been developed and used in commercial games. These input devices are based on motion, touch, tangibles, gaze, or brain control. Interestingly, papers included in the present review investigated only these new kinds of game control, and not more classic controllers. Most of the papers in this section (9) used experimental studies. Five papers described case studies and one paper used a survey. 
Several papers studied the impact of motion-based control in player-video game interactions. One characteristic of this type of control is that individuals play motion-based games not only for hedonic purposes but also for utilitarian purposes. Indeed, H.-H. Lin, Wang, and Chou (2012) showed with a survey that perceived exercise utility and perceived enjoyment during a motion-based game positively predict intentions to play in future. Furthermore, perceived motion-sensing of the game positively predicts both perceived exercise utility and perceived enjoyment. Bianchi-Berthouze (2013) experimentally showed that several types of players' movement can be categorized during game play, such as "task-control" body movement that is imposed by the game or "role-related" body movement that is not imposed by the game and is voluntary performed by the player. The author showed that every type of movement performed by players has a positive impact on engagement. But social factors may inhibit or enhance this relationship. In line with this study, Kleinsmith and Gillies (2013) experimentally showed that games in which players can customize the behavior of their characters using their own movements while playing the game made the players feel more engaged than games with pre-existing movements.

Players' movements can be detected by the game with different levels of motion interactivity. Indeed, different systems that detect individuals' movements and that are dedicated to gaming are nowadays commercialized. They can detect movements of the whole body or only parts of the body (e.g., arm movements). Two experimental papers studied the impact of level of interactivity on spatial presence, perceived realism and enjoyment. Shafer, Carbonara, and Popova (2011) showed that the level of motion interactivity predicts positively perceived realism, spatial presence and enjoyment. McGloin, Farrar, and Krcmar (2011) replicated these results by using the term "controller naturalness". They also showed that spatial presence, perceived realism and enjoyment were higher when players played with a motion-based controller than with a classic pad controller. In addition, Silva and El Saddik (2013) showed 
in a case study that smartphones are usable and acceptable motion-based controllers to play video games.

Interacting with the game by touching the screen is another common new way to play, especially with recent hand-held console games and mobile devices such as smartphones or tablets. Two experimental papers studied the implications of this information input on the player-video game interaction. Shafer (2013) showed that touch-based games displayed on mobile platforms produced higher perceived interactivity, perceived realism, and consequently enjoyment than traditional console games (i.e. with classic pad controller). However, in this study, the finding was limited by the confounded factor of screen size, which is an information output factor. Gao, Bianchi-Berthouze, and Meng (2012) explored the possibility of using the player's finger-stroke behaviors to capture his or her emotional state in touchbased video games. By comparing questionnaires and characteristics of actual finger-strokes, the authors showed that the finger-stroke behaviors allow discrimination of four tested affective states: excited, relaxed, frustrated, and bored. The length and pressure of the stroke discriminated two levels of valence (negative vs. positive). The speed and direction discriminated two levels of arousal (high vs. low). The pressure discriminated frustration from other emotional states. Length discriminated relaxed state from others. The authors assert that these results could be used in games that would take into account affective states of the player to generate content for the game in real time. Finally, in a case study, Raisamo, Patomäki, Hasu, and Pasto (2007) designed and evaluated a game for visually impaired children using a tactile device with vibro-tactile parameters. The authors showed that their system was usable for these children.

In line with tactile input, tangible interfaces were also studied in the literature. In a case study, Paiva et al. (2003) designed and evaluated a doll as a controller of emotional state of a synthetic character to interact with the video game world. The doll could be moved in different ways by the player according to 
the emotion he or she wanted to express. The authors showed that happiness, sadness and anger were performed easily by the players. However, other emotions such as fear or surprise were difficult to perform. The participants of the study seemed to like the doll as a game input device. The kids were even more enthusiastic than the adults.

Some authors have also designed and tested types of game control that are not used in mainstream commercial games yet, such as gaze control and brain control. Two experimental papers investigated the feasibility of gaze control in a simple arcade game. Dorr, Pomarjanschi, and Barth (2009) studied the feasibility of gaze control in a simple arcade game. They showed that in this case, gaze control is a valid input mechanism because no significant difference in performance was found between a classic controller, i.e. a mouse, and gaze control. San Agustin, Mateo, Hansen, and Villanueva (2009) replicated this finding. They even showed that, in addition, player performance was higher with gaze control than with a joystick, another classic controller. However, subjective ratings suggested players' discomfort with gaze input. This type of control was rated as fatiguing, in part because of the need to keep the head still for long periods of time. Vickers, Istance, and Hyrskykari (2013) showed in a case study that a complex game task, such as a moving a character in a 3D virtual world, can be performed in an acceptable way by young people with severe physical disabilities.

Maby, Perrin, Bertrand, Sanchez, and Mattout (2012) studied in a case study the validity of braincomputer interface $(\mathrm{BCl})$ input in a simple arcade two-player game. When using $\mathrm{BCls}$, players have to manipulate their brain activity to produce signals that control the game. The authors found that their device is a valid input method since the game can be effectively controlled, with a pace comparable to a manual type of control. However, as Van de Laar, Bos, Reuderink, Poel, and Nijholt (2013) point out, the system recognition of $\mathrm{BCl}$ input commands is still far from perfect. These authors investigated in an experimental study the influence of unreliable input on player experience. They simulated different 
amounts of (manual) control in a simple game. They showed that player frustration decreased and level of fun increased with increasing control. Interestingly, the authors showed that the level of fun dropped just before perfect control was reached. They concluded that (mildly) unreliable input could be used to create challenge in a game.

In summary, literature showed that information input and output techniques are essential parts of player-video game interactions, and widely studied. Regarding output information, the characteristics and quality of visual displays, such as characteristics of background (color, motion), head-up displays (location on the screen) and representation of virtual world (camera point of view), and auditory displays, such as sound and music, may influence players' performance, immersion, flow, and emotional state. Regarding input information, the way of game control, such as motion, tactile, tangible, by gaze, or by brain activity may influence players' performance, engagement, presence, perceived realism, and enjoyment.

All these data combine to show that video games are in some regards similar to other systems such as virtual environments since they have characteristics in common with these environments (e.g., Stanney, Mollaghasemi, Reeves, Breaux, \& Graeber, 2003). However, there are limits to this equivalence, and interactions with video games cannot be studied solely from the perspective of information input/output techniques, since video games unlike many other interfaces are meant to be entertainment. Other characteristics such as challenge and narrative, unique to games, were investigated by researchers as well.

\subsection{Game contents}

An important distinction between player-video game interaction and other $\mathrm{HCl}$ is characteristics of the game virtual world, such as game rules or mechanics (gameplay). Another key point is that video games 
are designed for entertainment purposes. Two main video game aspects concerning game contents were studied in the literature: challenge posed by the game and game narrative.

\subsubsection{Challenge and difficulty}

Challenge is a main part of the player-video game interaction. Unlike in typical $\mathrm{HCl}$, the task should not be simplified to the greatest possible extent in order to facilitate interaction, but should instead be sufficiently difficult to maintain player motivation (Malone \& Lepper, 1987). Four experimental papers studied the role of challenge in player-video game interactions.

In a video game, challenge is generally determined by the difficulty of the task to be performed. Qin, Rau, and Salvendy (2010) studied the effects of scenarios of varying difficulty on player immersion. They manipulated the difficulty of a video game level, which either increased constantly or alternately increased and then fell. These authors showed that player immersion was greater when the difficulty alternated than when it increased constantly. Liu, Agrawal, Sarkar, and Chen (2009) compared two systems of "dynamic difficulty", in which the difficulty variation was based either on changes in the player's performance or on changes in his or her level of anxiety (based on physiological measurements). These authors showed that the player's subjective experience was better when the difficulty of the game varied as a function of anxiety level rather than as a function of his or her real performance. Similarly, Shaker, Asteriadis, Yannakakis, and Karpouzis (2013) found that dynamic difficulty in games can be based on player experience (i.e. engagement, frustration) extracted from the visual and facial behavioral and expressivity patterns of the player.

Challenge can also be created by manipulating fairness in a video game. De Simone, Verbruggen, Kuo, and Mutlu (2012) studied the influence of a cheating game on the player's presence, enjoyment, state hostility and perceived humanness of the game. Participants played either a regular game (i.e. the rules were always the same for the player and the computer opponent) or a cheating game (i.e. rules could 
vary to give the advantage to the computer opponent). Players' presence and perceived humanness of the computer opponent were higher in the cheating condition than in the regular one. However, there was no difference in enjoyment and state hostility between the two conditions.

\subsubsection{Narrative and gameplay}

Stories are often present in video games. The game narrative can be an embedded storyline in the game (linear or not), and can also emerge in the course of gameplay (Pagulayan et al., 2012). Choi, Huang, Jeffrey, and Baek (2013) showed with a survey that fantasy plays a essential role in player-video game interactions by enhancing motivation and immersion in gameplay. The authors designed and validated a scale for fantasy state in games based on four factors: identification, imagination, analogy and satisfaction.

Two experimental papers and a survey paper investigated the role of narrative and gameplay in playervideo game interactions. Park, Lee, Jin, and Kang (2010) showed that the presentation of a narrative context during the introduction of a video game increased the player's presence compared to a situation in which no such story was presented or the player saw a technical presentation of the game completely disconnected from the narrative context. Increased player presence resulted in an improved overall evaluation of the game. Gameplay design choices also have an influence on player presence. Balakrishnan and Sundar (2011) manipulated the navigational affordances in the virtual world of the game, namely the environmental constraints ("physical" rules of the virtual world), the steering control (ability to modify one's viewpoint in the environment) and guidance (information provided by the game). The results showed that only the variation of steering control has a significant influence on presence. The more possibilities the player had to move in the virtual world, the more he or she felt presence.

In summary, literature showed that specific features of video games such as challenge, narrative and gameplay influence players' experience. Challenge can be determined by manipulating difficulty, with 
static or dynamic variation, or fairness in the game, and influences players' immersion, presence, enjoyment and emotional state. More precisely, dynamic difficulty is more influent when it is based on actual experience of players. Narrative design in games, such as level of fantasy of presence of narrative context, influences players' immersion and presence. Finally, gameplay design, such as navigational affordances, influences players' presence.

Aspects of challenge and narrative are common to all player-video game interactions. However, there are also certain gameplay situations that mobilize specific concepts such as multiplayer situations, which are presented in the following section.

\subsection{Multiplayer games}

In some cases, several players can share their interaction with a video game. Multiplayer games, which account for a large proportion of the video games market, raise specific problems in terms of interaction. It is necessary to consider two types of multiplayer situation: the players may all be physically located in the same place ("local" situation) or may be connected online via the Internet. In the case of local situations, several different players can play with the same system on the same screen or with several different connected systems. When playing online, several players can play in the same virtual world while using different systems connected via the Internet. These multiplayer game situations pose different sorts of problems.

\subsubsection{Local multiplayer games}

Several papers showed that in local multiplayer games, the nature of the game (cooperative/competitive) and the nature of the game partner (friend, stranger or computer) have an influence on the game player experience. Most of them (5) used experimental studies and one paper used a survey. 
Chanel, Kivikangas, and Ravaja (2012) demonstrated that player experience, based on physiological measures and questionnaires, is different depending upon whether the game has competitive or cooperative rules. Physiological measures revealed that the signals from facial electromyography, electrocardiogram and respiration were higher in the competitive game than in the cooperative game. Higher negative and positive feelings were observed in the competitive game as compared to the cooperative game. Song, Kim, Tenzek, and Lee (2013) studied more precisely the effect of competitive games on players' intrinsic motivation to play motion-based games. The authors showed that intrinsic motivation was higher when the game was played in an explicit competitive context than when there was no competition, but only when players had high individual competitiveness. Von der Pütten et al. (2012) studied more precisely collaborative games with a survey investigating the link between presence and physical behaviors of players when they play in pairs. The authors showed that some types of behaviors, such as pointing at the screen or verbally responding to the virtual content, were connected negatively to sense of presence. This kind of behavior indicated that the feeling of being in the game was weak. In contrast, no kind of behavior correlated positively with the sense of presence in this study.

In addition to the nature of game, the nature of the gameplay partner also has an impact on player experience. Ravaja et al. (2006) showed that in a competitive game, players' presence was greater when the opponent was controlled by a human player than when it was controlled by the computer. Also, the level of presence was greater when the opponent was a friend than when it was an unknown person. Furthermore, Kivikangas and Ravaja (2013) showed that a defeat or a victory elicit different emotional responses according to the nature of the opponent. A defeat elicited increasing positive affect and decreasing negative affect regardless of opponent type. In contrast, a victory elicited increasing positive and negative affect when the opponent was a friend. Defeat and victory elicited basically similar emotional patterns when the opponent was a stranger or a computer. Concerning collaborative games, 
Peng and Hsieh (2012) showed a stronger commitment to the in-game goals when players were friends than they were strangers. This effect was not observed with a competitive game.

\subsubsection{Online multiplayer games}

Nowadays, game systems usually give players the option of playing together with others via networks such as the Internet. There are a number of points that are specific to player-online video game interactions. This places players in a special situation both with regard to the video game itself and the other players involved. Methodology to study online games was quite diverse. Literature review revealed that five survey papers studied motivation to play online games, three experimental papers studied the influence of the nature of the game partner (friend, stranger or computer) on the player experience, two experimental papers studied video-mediation between players, two qualitative and one survey papers studied the specific nature of massively multiplayer online games (MMOG), and one experimental paper studied the influence of specific technical issues on player experience.

Motivation to play online games was studied in five papers, all using survey methodology. Koo (2009) showed that perceived enjoyment, perceived escape from life boredom and perceived social enjoyment (result of socializing with other online game players) are three significant factors of intention to play an online game. In addition, Shin and Shin (2011) showed that perceived usefulness of the game is also a significant factor. These authors showed that flow is a moderator between these factors and intention to play this kind of games. Voiskounsky, Mitina, and Avetisova (2004) studied flow experience in multiplayer online games. They proposed and validated a model of flow that was composed of five dimensions: Achievement (desire to acquire achievements while playing), activity/passivity (constant strict control, or not, over situations taking place in the game), interaction (orientation towards communication with other players), thoughtfulness/spontaneity (reflections, or not, about the situations taking place in the game), cognition (interest and pleasure while playing online games). Factors that incite players to continue to play online games were also studied. M.-C. Lee and Tsai (2010) showed that 
continued intention was predicted positively by, among other factors, the player's perceived enjoyment and flow experience. Furthermore, perceived ease of use positively predicted perceived enjoyment. Interactivity with the game and social interaction positively predicted flow experience. Possibility of game customization has also positive influence on loyalty (Teng, 2010).

As in local multiplayer gaming, the influence of the nature of the partner player on the game player experience was studied in three experimental papers. Weibel, Wissmath, Habegger, Steiner, and Groner (2008) studied the influence of the nature of the opponent on the player's presence, flow and enjoyment in an online game. Participants played a game against a computer opponent. However the authors manipulated the participants' beliefs by indicating that the opponent was controlled either by a human player or by the computer. The authors showed that presence, flow and enjoyment were higher when the player believed that the opponent was a human player than a computer one. Cairns, Cox, Day, Martin, and Perryman (2013) replicated these results with immersion. Immersion was higher when the opponent was controlled by a human. Finally, Lim and Reeves (2010) replicated these results by measuring the emotional responses of players. They showed that players were more emotionally engaged when they believed that the opponent was controlled by a human. They also showed that in terms of emotional valence, presence and preference, the player experience was better in a competitive game when players thought they were playing with a human being, whereas there was no difference between human and computer in a cooperative game.

Two experimental papers studied the influence of video mediated playing, which can take place in online multiplayer games, on player experience. Derboven, Van Gils, and De Grooff (2011) studied players' experience in video-mediated multiplayer games when one of the players is elderly. The authors compared the experience of two players (an elderly person and his or her child or grandchild) who played a classic memory game with or without video chat. The results showed that the game was judged 
more collaborative with video chat. Furthermore, the players preferred the video chat game. The (grand)child preferred even more this condition than the condition without video chat. The authors explained these results by the fact that it is rewarding for the younger player to guide the elderly one and to share knowledge. Shahid, Krahmer, and Swerts (2012) studied the influence of mutual gaze in video-mediated playing on social presence with children. In this study, players could see each other on the screen but in one situation they could see their mutual gaze (gaze condition) and in the other case they could only see the other player in profile (non-gaze condition). The authors showed that social presence, fun, engagement and endurability (interest in playing the game again and again) were higher in the gaze condition than in the non-gaze one. Interestingly, the results also showed that fun, engagement and endurability were higher for the gaze condition than for a condition where players played on the same computer (local situation). The authors explained this by the fact that children have to work harder to communicate when they play in physical co-presence. Thus, this situation has a negative impact on fun, engagement and endurability.

One somewhat recent genre has been able to claim an important place among online games. This genre, the MMOG (Massively Multiplayer Online Game), can allow thousands of players to interact within the same virtual world. Three papers reported three new research questions raised by this specific characteristic. First, Billieux et al. (2013) used a survey to examine motives to play these games. They showed that players' motives are mainly oriented toward teamwork and competition. Second, Christou, Lai-Chong Law, Zaphiris, and Ang (2013), in a qualitative study, showed that features of sociability should be the first objective of game design. Six requirements are proposed to enhance player experience in MMOG: in-game communication, off-game communication, empathy, grouping and rewards, world design, and designed relationships. Third, Ang, Zaphiris, and Mahmood (2007) conducted a qualitative study to examine the cognitive load of players in a MMOG situation. The authors showed that the cognitive load in this kind of game has four main origins: multiple interactions with the virtual world, 
interaction with the user interface, social interaction with other players, and building the player's avatar identity and those of other players.

Finally, all kinds of online games are source of issues linked to technical anomalies of large computer networks such as the Internet. In an experimental paper, Chung and Gardner (2012) studied the temporal variations of the presence experience of players due to sudden and temporary technical anomalies that can appear in networked gaming, such as decrease of screen frame rate, sound absence, reverse control of the game or screen and sound blackout. These periods of disruption of presence are called breaks in presence. The results showed that the breaks in presence differed in intensity and in length depending of the nature of the anomaly and the game task (navigation or combat). In sum, low frame rate and blackout generally had more impact on presence. The impact was higher when the anomaly, such as low frame rate, disrupted the mission-critical goal of survival in combat. The authors also showed that the length of breaks in presence were lower when the participants had higher scores for focus and involvement.

In summary, literature showed that multiplayer games raise specific concepts that influence player experience. First, whether the game has competitive or collaborative rules, motivations to play and player experience are different. Second, players' presence, immersion, enjoyment, and emotional responses are higher when they played with or against a human player than a computer one. Players' presence and emotional responses are even higher when the opponent is a friend than a stranger. Finally, motivations to play online games, and especially MMOG, are mainly linked to social interactions. In online games, video-mediation between players contributes to improve player experience.

The five first sections of the results were dedicated to articles that studied isolated (human or machine) aspects of player-video game interaction. The following section is focused on articles that had a holistic approach to this interaction. 


\subsection{Global approaches to player-video game interaction}

Some authors aimed to study the whole player-video game interaction. Literature showed that some of these studies proposed new concepts to characterize player-video game interactions such as playability. They can be derived from the more widely used usability or user experience concepts. Other studies proposed new methods to evaluate the global quality of player-video game interaction.

\subsubsection{From usability to user experience in the study of player-video game}

\section{interactions}

The main concept underpinning the user-centered design of traditional interactive systems is usability (e.g., Hornbæk, 2006; Shackel, 2009). According to the ISO 9241-11 standard (International Organization for Standardization, 1998), the usability of a system consists of three main criteria. It must enable users to achieve their goals (effectiveness), perform their task with a minimum of resources (efficiency) and, finally, to enjoy a positive feeling during the completion of the task (satisfaction). Usability is one important aspect of understanding and evaluating player-video game interaction (Isbister \& Schaffer, 2008). Nevertheless, for several authors, the concept of usability is not sufficient when it comes to designing video games, the aim of which is entertainment (e.g., Pagulayan et al., 2012). Efficiency and effectiveness are useful measures for task-based systems, but less so for systems that aim to create an entertaining moment-to-moment and overall experience. Another concept, "user experience", is increasingly being used today for the study of systems that are not focused exclusively on productivity (Hassenzahl, Diefenbach, \& Göritz, 2010; Hassenzahl \& Tractinsky, 2006). According to the ISO 9241-210 standard (International Organization for Standardization, 2010), user experience corresponds to the perceptions and responses resulting from the use or the anticipated use of a product, system or service. Studies of player-game interactions now seem to favor this concept over that of usability (Bernhaupt, 2010). However, a number of works have proposed alternatives to the concepts of usability and user experience in the field of video game design. 


\subsubsection{Usability models suitable for the video game context}

The concept of user experience can be used to study all types of $\mathrm{HCl}$. However, additional models have been proposed for the study of player-video game interactions. The aim of these models, which are presented in the current section, is to take into account specific characteristics of player-video game interactions, such as enjoyment and challenge, as extensively and as precisely as possible.

An initial approach retains the criteria of usability as applied to conventional interfaces while simultaneously giving them a new meaning. González Sánchez, Vela, Simarro, and Padilla-Zea (2012) suggested developing the concept of usability toward a concept of "playability", which is similar to the concept of user experience used for interactive systems in general. These authors defined the playability of a video game as the degree to which users can achieve goals effectively, efficiently and, most importantly, with satisfaction and fun within a playful context of use. The playability model is composed of seven attributes. In addition to the attribute of effectiveness, this approach holds that the criterion of efficiency should be subdivided into two distinct attributes (learnability and immersion), and the criterion of satisfaction into 4 attributes (satisfaction, motivation, emotion and socialization). They validated their concept with a case study.

A second approach, which complements the user-centered design of video games, is developing explanatory models of the ways players use games. Based on qualitative studies, three models describe the various elements present in a player-video game interaction. Fabricatore, Nussbaum, and Rosas (2002) proposed a model of playability that brings together key aspects of game design that are based on players' preferences. They were able to identify a hierarchical model of the parameters that influence playability, subdivided into three categories: the parameters associated with the interface, those associated with the scenario and those linked to the hierarchical organization of the goals. For their part, Barr et al. (2007) suggested qualifying the player-game interaction in terms of "values", which would correspond to the specific objectives pursued by the players depending on the type of video game 
played. For example, in "role-playing" games, there are three values that give players the impression that they are progressing in the game: completing quests, exploring the world, and improving the level of their avatars. Nevertheless, the concept of value is difficult to work with because each type of game would possess its own values. Finally, Y.-L. Lin and Lin (2011) proposed a "hierarchical value map" to qualify the more specific player-game interaction in massively multiplayer online role-playing games (MMORPGs). This hierarchical value map consisted of 10 attributes, 11 perceived consequences and 9 personal values, which are interconnected. More precisely, attributes are the physical or intangible characteristics of the game (e.g., interface design, multiplayer gaming). Perceived consequences can be functional (e.g., enhanced efficiency) or psychosocial (e.g., enhanced interaction). The values are players' desired end-state (e.g., warm relationships with others).

\subsubsection{Methods used in the design and evaluation of player-video game interaction}

Currently, video game designers may adopt a range of methods within the framework of a user-centered approach (Isbister and Schaffer 2008; Bernhaupt 2010). Even if there is no consensus with regard to the criteria used for the study of human-computer or player-video game interactions (see previous subsection), the majority of methods, such as user tests and heuristic evaluations, are nevertheless adopted by all designers (Hornbæk, 2006).

Two papers adapted classic user testing to test video game usability. Barendregt, Bekker, Bouwhuis, and Baauw (2006), in an experimental study, suggested testing the usability of a game twice with the same player. They reported that the problems before and after some practice were different in terms of quality and severity. During the first use, the problems tended to be primarily related to players' knowledge and level of challenge, which can block the progression of players. After some practice problems of fun appeared, but without blocking the progression of the player. The players could be bored by the repetitiveness of the game mechanics or the decrease of challenge for example. In a case study paper, Höysniemi, Hämäläinen, and Turkki (2003) proposed a collaborative method to test the 
usability of video games with children: "peer tutoring". The method is based on the assertion that children naturally gather to play games. In this method, usability problems are measured while a child teaches the game to another child. The game is usable if a child is able to teach another child how to use it. However this method is expensive in terms of time and patience with children.

Finally, Pavlas, Jentsch, Salas, Fiore, and Sims (2012) used a survey to develop a new scale to measure play experience in video games : the "play experience scale". They built their scale using five dimensions of play experience based on the literature. These dimensions are autotelic experience (i.e. intrinsic motivation of a player to play a game), freedom of the player, focus of the player (e.g., immersion, attentional narrowing), absence of extrinsic motivation (by rewards or consequences) and direct play assessment (i.e. the player believed he or she engaged in play).

In summary, literature showed that several different concepts were proposed to characterize the whole player-video game interaction. First, the concept of playability was proposed, but with two different definitions. Playability can be an adaptation of usability adapted for playful context of use, or a new model that brings together key aspects of game design that are based on players' preferences. Second, player-video interactions could be qualified in terms of values, which correspond to players' specific objectives or desired end-state during the game play. Even if all these concepts seem heterogeneous and rather remote to classic usability or user experience, methods used to evaluate player-video game interactions are more typical. User testing was adapted - in particular to detect fun problems or to test games with children - and a scale to measure player experience was designed. 


\section{DISCUSSION}

The goal of the present article was to provide a systematic review of empirical evidence of current concepts of player-video game interactions taken from articles in scientific journals. Synthesizing the results allowed us to propose a clearer framing definition of player-video game interactions. Player-video game interactions are interactions in which technical aspects of video games have influence on players' engagement and enjoyment (Figure 1). Findings reported in the present review demonstrate that player aspects (engagement and enjoyment) and video game aspects (information input/output, content and multiplayer techniques) serve as a frame for several detailed sub-concepts that can be examined independently (or in combination). Findings also revealed that some researchers take global approaches to analyzing player-video game interactions, such as by examining playability.

The present review included 72 articles that were published from 2000 through 2013, with more than half of them published from 2010. Interestingly, although video games have existed for four decades, most studies about the nature of player-video game interactions are recent. They are much more recent than studies about the negative effects of using video games on the player's behavior for example, which emerged in the late 1980s (see Anderson et al. 2010 for a review). The following paragraphs provide implications for researchers and offer questions to help guide future empirical studies about the intrinsic nature of player-video game interactions. Practical implications are presented to help game designers to optimize the design of player-video game interactions. Finally, perspectives and ideas for further literature reviews are proposed.

\subsection{Research implications}

Results of the present review showed advances in the field so far in qualifying player-video game interactions. However, this review also allows the community to see what facets need further research. First, this review revealed some important limitations of findings that may prevent their being 
completely accepted by the community. For example, weakness of study methodology and lack of replication could limit validity of findings. Also, findings could have low impact because of a problem of generalizability, feasibility, external validity, or problems of adaptation or correspondence of concepts also studied in other areas of $\mathrm{HCl}$. This review also revealed a lack of advances in research, particularly in regard to recent technological innovations in player-video game interactions. The following paragraphs explore topics that need further research studies in order to better understand player-video game interactions.

\subsubsection{Limitations of validity of findings}

The first limitation of validity of the literature findings is due to the heterogeneity of methodologies used in the papers. Surveys and experiments were the most commonly used methods to study different aspect of player-video game interactions. More precisely, surveys were mostly used to study player aspects while experimental studies were mostly used to investigate video game aspects. Nine of the twelve papers that studied concepts of engagement or enjoyment used surveys. In contrast, thirty-seven of the fifty papers that studied input/output information, game contents or multiplayer games used experiments. In general, the authors argued that the use of a survey is a necessary step to explore and discover elements underpinning a particular concept. The use of experiments seemed to be more logical to study game aspects since the main goal of authors was to test how manipulating a particular game aspect affected player aspects. However, most of the player concepts studied in the papers included in the present review have already been explored in other areas of $\mathrm{HCl}$. For this reason, studies of player aspects themselves could have been more robust if they also used experimental methodology instead of surveys. A good practice for future research about player aspects would be to systematically use experiments. A good example is Jennett et al. (2008) who studied the nature and quality of immersion in video gaming in a multi-experiment paper using eye-tracking. 
A second limitation is the lack of replication of findings. Using a controlled experiment is not always sufficient. In the present review, several specific video game aspects (e.g., auditory information, tactile input) were tested in a few, or even only one, single-experiment papers. It is difficult for the community to use these findings since they are not reliable enough. In particular, studies about auditory displays, tactile or tangible control, control by gaze, and control by brain activity raised interesting topics, but report isolated results. Similarly, aspects such as the nature of game rules (cooperative/collaboration) or the specificities of online games were studied in several papers, but in a so different a way that comparison is difficult. In contrast, several effects have been widely tested and replicated. In particular, the concepts of visual displays (nine experimental papers and a case study), motion-based control (four experimental papers, a survey paper, and a case study), game difficulty (three experimental papers), the nature of opponent (six experimental papers, including a three-experiment one), and video-mediation (two experimental papers) were studied in several times in a similar way. The consequence is that results of the latter papers can be easily trusted and used by game designers (see practical implications below). In conclusion, further effort is necessary to design research that replicates the more isolated findings in order to confirm or refute them.

\subsubsection{Limitations of impact of findings}

Findings of several papers in the present review could have limited impact, not because of a lack of strong methodology, but because of a lack of generalizable results. The lack of generalizability can be due to studies that investigated overly specific player populations, game situations, or types of video game. A first example concerns papers that studied video-mediation in online multiplayer games. The targeted population of these studies was children or older adults. It would be difficult to generalize the findings to the main population of players, which is composed of teenagers and young adults. A second example concerns papers that studied visual displays of games (backgrounds and HUDs). In general, authors used very simple games and visual stimuli in their experiments. Thus, it could be difficult to 
generalize their findings to commercial games, which are more complex in terms of visual design and game design.

A limited impact can also be due to the lack of feasibility for further studies because of prohibitive constraints. For example, the review showed that physiological measures are a useful measure of player emotion. However, this method is invasive and requires expensive equipment and complex data analyses. Furthermore, other authors have proposed more flexible methods for measuring the emotional state of players during gameplay. Isbister and her colleagues (Isbister, Höök, Laaksolahti, \& Sharp, 2007; Isbister, Höök, Sharp, \& Laaksolahti, 2006) used a subjective, non-verbal indicator of emotional state: "the sensual evaluation instrument". This instrument makes use of a number of different objects that can be handled and which are designed in such a way that their physical characteristics can correspond to the various emotions experienced by players. Similarly, the use of gaze or brain to control the game could be limited for further research since this method is restricting and needs more evidences to be more accepted. The lack of feasibility can also be due to the absence of control of the game situation by game designers. Typically, findings about screen or sound quality, such as screen size or number of sound channels, have a limited impact on game design, because game designers do not always have the possibility to modify the screen or the sound system players use to play video games.

Finally, findings can have a limited impact because of problems of adaptation or correspondence of concepts also studied in other areas of $\mathrm{HCl}$. Two major examples of such a problem were revealed by the review. First, concerning global approaches to player-video game interaction, the definition of playability is still debated (e.g., Zhu \& Fang, 2014). The models presented in the present review propose alternative views concerning the usability of video games, and it is difficult to evaluate their respective benefits because each of them advocates a different approach and uses different concepts. It is necessary to ask whether the case of video games really requires us to redefine the concept of usability. It appears to be 
less pressing to attempt to redefine usability since the concept of user experience has already been adopted to qualify $\mathrm{HCl}$ practices. Second, concerning the player aspects of player-video game interactions, the boundary between the concepts of immersion and presence remains vague in the majority of studies because these terms are often used interchangeably even though the distinction between the two concepts is real in other $\mathrm{HCl}$ areas (Stanney et al., 2003). Immersion is directly linked to the characteristics of the system (e.g., size of the screen, sound volume), whereas presence is associated with the user's desire "to be in the environment". However, this difference has only rarely been explicitly defined in the literature on video games (e.g., E. A. Boyle et al., 2012). Cairns et al. (2013) also wrote in detail about this issue.

There are two types of negative consequences of misusing well-established concepts, or initiating and studying new game-specific concepts instead of using established concepts from other areas of $\mathrm{HCl}$. First, in that case, findings from player-video game studies cannot benefit the entire $\mathrm{HCl}$ community. The present review focused on video game playing in entertainment situations. However, the results of papers based on established concepts could be interesting and applicable to other gaming situations or other areas of $\mathrm{HCl}$. Second, new game-specific concepts may need new methods or tools of measurement (such as new questionnaires). However, the design, development and evaluation of such methods or tools may have a significant cost. The time and means involved in their development should be avoided where possible, and allocated to other topics of research.

\subsubsection{Lack of research advances}

The present review revealed lack of advances in research, especially in regard to recent technological innovations. Typically, the most recent innovations are related to input/output techniques. Recent input techniques have been globally well studied. For example, motion-based gaming was studied in four experimental papers, one survey paper and one case study paper. In contrast, recent output techniques have been less studied and need more empirical studies to better understand their role in player-video 
game interactions For example, 3D stereoscopy (e.g., Takatalo, Kawai, Kaistinen, Nyman, \& Hakkinen, 2011) and virtual reality head-mounted displays (e.g., Merhi, Faugloire, Flanagan, \& Stoffregen, 2007) are recent innovations in game design that need more documentation.

Moreover, it is interesting to note that several not-very-recent technological innovations for input/output information have been studied in very few studies or none at all. The most surprising example is the absence of research on the classic controllers used in video games, such as gamepads, joysticks, and keyboard and mouse. Paradoxically, new input techniques such as control by gaze or by brain activity, which have not been used in commercial games and for which future implementation is still questionable, were studied in several papers. Output techniques other than visual displays also received little attention. Auditory output technique was studied in only two papers, and haptic techniques such as vibrations or haptic feedback were not studied. Finally, multimodal interactions, which have been broadly studied in other areas of $\mathrm{HCl}$, were not studied either.

In a similar way, several gameplay innovations that have been regularly integrated in video game design need more empirical studies. The most remarkable recent innovations are mainly linked to the popularization of the Internet in electronic systems. For example, social networks now play an important role in video games whether multiplayer or not. Literature has largely studied the intention or motivation of players to play online social games (e.g., Koo, 2009). However, more empirical evidence is needed to document the role in player-video game interactions of, for example, social networks in single player or multiplayer games (e.g., De Kort \& Ijsselsteijn, 2008), personal avatar creation (e.g., Trepte \& Reinecke, 2010), and gameplay personalization in general (e.g., Yannakakis \& Hallam, 2007).

In summary, the present review showed a high diversity of topics and approaches to study player-video game interactions. However, some limitations of validity and impact of findings, but also a lack of research advances for some concepts were observed. Future research could increase convergence of 
findings and further improve the general quality of research in this area. First, research design should be as rigorous and reliable as possible. Experimental studies and replication studies could be undertaken more frequently. Second, research should be designed to obtain findings with a higher impact. Some findings should be more generalizable and usable without prohibitive constraints where possible. Concepts and methods existing in other areas of $\mathrm{HCl}$ could be used more frequently for player-video interactions where relevant. Third, some under-examined concepts of player-video game interactions could be investigated. Several input/output techniques and social game design in particular need more empirical evidence.

\subsection{Practical implications}

The present systematic review can help game designers to optimize their design of player-video game interactions. We have crafted game design recommendations designed on the basis of the results reported in the review, when applicable. These recommendations are displayed in table 1. Each recommendation was based on one result for which a significant effect of the manipulation of a video game aspect on a player aspect was reported in at least two experiments (i.e. in a multi-experiment paper or in two or more different experimental papers). This constraint was defined to avoid findings that were not replicated (see previous section). The resultant recommendations were categorized according to the respective video game aspect, namely visual output, input technique, game challenge, game narrative, and online multiplayer games.

[Insert Table 1 near here] 
Second, different methods to measure player aspects of player-video game interaction were used or proposed by authors of the studies included in the present review. Game designers should be careful in their choices, which should be selected in close connection with the expected impact of their own game design on players. Table 2 shows the relations between methods and player aspects that could be measured. For example, the questionnaire method can be relevant to measure all player aspects. But, more specific objective measures such as eye-tracking or physiological measures have to be used only for a specific player aspect, respectively for immersion and emotions. Note that several studies used or proposed two or more methods to measure the same player aspect (see Caroux \& Isbister, 2014 for a specific review).

[Insert Table 2 near here]

\subsection{Perspectives}

The present literature review was limited to articles that presented empirical evidence about the nature of player-video game interaction in entertainment situations, and that were published in scientific journals indexed in databases connected to $\mathrm{HCl}$. However, several concepts studied in this review were already studied in and are applicable to other subdomains of $\mathrm{HCl}$. A good example is the concepts linked to engagement, such as presence and immersion. They have been designed and also studied outside the scope of video games. Thus, findings reported in the present review could be used (cautiously) for other $\mathrm{HCl}$ contexts. Of course, findings from other $\mathrm{HCl}$ areas could also be used for player-video game interactions. 
Furthermore, further literature reviews could bring other points of view regarding the links between players and video games. As specified in the method section, the present review excluded studies about serious games, educational games, games culture, nature of games, or nature of players. Each of these topics could be covered by a specific review. To do so, other sources could be used according to the topic of the review, such as academic journals in other areas than $\mathrm{HCl}$ (e.g., culture and communications, learning and instruction), conferences or professional publications. 


\section{CONCLUSION}

The high number of studies published in the field of player-video game interactions clearly shows that it is becoming an increasingly important area of research for the scientific community interested in $\mathrm{HCl}$. This systematic literature review revealed the complexity of the nature of player-video game interaction that is defined with multiple concepts that are closely linked and intertwined. The results allowed us to propose a definition of player-video game interactions. Player-video game interactions are interactions in which technical aspects of video games have influence on players' engagement and enjoyment. The present results may help practitioners such as game designers to benefit from knowledge of best practices in terms of knowledge and methodology. However, several limitations were revealed in the validity of findings, the impact of findings and the lack of research advances in regard to recent technological innovations. These limitations were discussed in particular to help researchers to plan future advances of the field and provide supplementary effort to better know the role of less-studied aspects of player-video game interactions. Finally, further literature reviews are necessary to gather and refine our overall knowledge, as advances continue to be made. 


\section{ACKNOWLEDGMENTS}

Loïc Caroux was supported by a PhD fellowship and a postdoctoral research fellowship from the Direction Générale de l’Armement (France). 


\section{APPENDIX}

\section{List of journals included in the search database}

\begin{tabular}{|c|c|c|c|c|}
\hline \multirow[b]{2}{*}{ Journal name } & \multicolumn{3}{|c|}{ Indexes } & \multirow[b]{2}{*}{$\begin{array}{l}\text { Number of articles } \\
\text { included in the } \\
\text { review }\end{array}$} \\
\hline & HCl Bibliography & $\begin{array}{c}\text { Science Citation } \\
\text { Index Expanded - } \\
\text { Computer } \\
\text { Science, } \\
\text { Cybernetics } \\
\end{array}$ & $\begin{array}{c}\text { Social Sciences } \\
\text { Citation Index - } \\
\text { Ergonomics }\end{array}$ & \\
\hline Accident Analysis \& Prevention & & & $\mathrm{x}$ & - \\
\hline ACM SIGDOC *Journal of Computer Documentation & $\mathrm{x}$ & & & - \\
\hline ACM Transactions on Accessible Computing & $\mathrm{x}$ & & & 1 \\
\hline ACM Transactions on Computer-Human Interaction & $x$ & $x$ & & 1 \\
\hline ACM Transactions on Graphics & $\mathrm{x}$ & & & - \\
\hline ACM Transactions on Information Systems & $\mathrm{x}$ & & & - \\
\hline ACM Transactions on Interactive Intelligent Systems & $\mathrm{x}$ & & & - \\
\hline ACM Transactions on the Web & $\mathrm{x}$ & & & - \\
\hline Advances in Human-Computer Interaction & $\mathrm{x}$ & & & 1 \\
\hline AIS Transactions on Human-Computer Interaction & $\mathrm{x}$ & & & - \\
\hline Applied Ergonomics & & & $\mathrm{x}$ & - \\
\hline Behaviour \& Information Technology & $\mathrm{x}$ & $\mathrm{x}$ & $\mathrm{x}$ & 3 \\
\hline Biological Cybernetics & & $\mathrm{x}$ & & - \\
\hline Cognition, Technology \& Work & & & $\mathrm{x}$ & - \\
\hline Cognitive Science & $\mathrm{x}$ & & & - \\
\hline Communications of the ACM & $\mathrm{x}$ & & & - \\
\hline Computer & $\mathrm{x}$ & & & - \\
\hline Computer Supported Cooperative Work & $\mathrm{x}$ & & & - \\
\hline Computers in Human Behavior & $\mathrm{x}$ & & & 13 \\
\hline Cybernetics and Systems & & $\mathrm{x}$ & & - \\
\hline Ergonomics & & & $\mathrm{x}$ & 2 \\
\hline Foundations and Trends in Human-Computer Interaction & $\mathrm{x}$ & & & - \\
\hline Human Factors & $\mathrm{x}$ & & $\mathrm{x}$ & 2 \\
\hline Human Factors and Ergonomics in Manufacturing \& Service Industries & & & $\mathrm{x}$ & - \\
\hline Human-Computer Interaction & $\mathrm{x}$ & $\mathrm{x}$ & & 4 \\
\hline Hypermedia & $\mathrm{x}$ & & & - \\
\hline IEEE Internet Computing & $\mathrm{x}$ & & & - \\
\hline IEEE Software & $\mathrm{x}$ & & & - \\
\hline IEEE Transactions on Affective Computing & & $\mathrm{x}$ & & - \\
\hline IEEE Transactions on Cybernetics & & $\mathrm{x}$ & & 2 \\
\hline IEEE Transactions on Haptics & & $\mathrm{x}$ & & - \\
\hline IEEE Transactions on Human-Machine Systems & & $\mathrm{x}$ & & - \\
\hline IEEE Transactions on Systems Man Cybernetics-Systems & & $\mathrm{x}$ & & - \\
\hline Interacting with Computers & $\mathrm{x}$ & $\mathrm{x}$ & $\mathrm{x}$ & 12 \\
\hline Interactions & $\mathrm{x}$ & & & - \\
\hline International Journal of Human-Computer Interaction & $\mathrm{x}$ & $\mathrm{x}$ & $\mathrm{x}$ & 7 \\
\hline International Journal of Human-Computer Studies & $\mathrm{x}$ & $\mathrm{x}$ & $\mathrm{x}$ & 8 \\
\hline International Journal of Industrial Ergonomics & & & $\mathrm{x}$ & - \\
\hline International Journal of Man-Machine Studies & $\mathrm{x}$ & & & - \\
\hline International Journal of Mobile Human Computer Interaction & $\mathrm{x}$ & & & - \\
\hline International Journal of Occupational Safety and Ergonomics & & & $\mathrm{x}$ & - \\
\hline Journal of Computer and Systems Sciences International & & $\mathrm{x}$ & & - \\
\hline Journal of Organizational Computing and Electronic Commerce & $x$ & & & - \\
\hline Journal of Safety Research & & & $\mathrm{x}$ & - \\
\hline Journal of Usability Studies & $\mathrm{x}$ & & & - \\
\hline Journal of Visual Languages and Computing & $\mathrm{x}$ & & & - \\
\hline Journal on Multimodal User Interfaces & & $\mathrm{x}$ & & - \\
\hline Kybernetes & & $\mathrm{x}$ & & - \\
\hline Kybernetika & & $\mathrm{x}$ & & - \\
\hline Machine Vision and Applications & & $\mathrm{x}$ & & - \\
\hline Modeling Identification and Control & & $\mathrm{x}$ & & - \\
\hline Multimedia Systems & $\mathrm{x}$ & & & 2 \\
\hline
\end{tabular}


New Review of Hypermedia and Multimedia

New Technology, Work and Employment

Presence: Teleoperators and Virtual Environments

PsychNology Journal

Romanian Journal of Human-Computer Interaction

SIGCHI bulletin

SIGIR Forum

Travail Humain

Universal Access in the Information Society

User Modeling and User-Adapted Interaction

Virtual Reality

\begin{tabular}{lll} 
& $x$ & - \\
$x$ & & - \\
& & 8 \\
& & - \\
& & - \\
$x$ & $x$ & - \\
$x$ & $x$ & - \\
$x$ & & 1 \\
\hline
\end{tabular}




\section{REFERENCES}

* denotes a reference among the reviewed studies

Anderson, C. A., Shibuya, A., Ihori, N., Swing, E. L., Bushman, B. J., Sakamoto, A., ... Saleem, M. (2010). Violent video game effects on aggression, empathy, and prosocial behavior in Eastern and Western countries: A meta-analytic review. Psychological Bulletin, 136, 151173. doi:10.1037/a0018251

*Ang, C. S., Zaphiris, P., \& Mahmood, S. (2007). A model of cognitive loads in massively multiplayer online role playing games. Interacting with Computers, 19, 167-179. doi:10.1016/j.intcom.2006.08.006

*Bae, S., Lee, H., Park, H., Cho, H., Park, J., \& Kim, J. (2012). The effects of egocentric and allocentric representations on presence and perceived realism: Tested in stereoscopic 3D games. Interacting with Computers, 24, 251-264. doi:10.1016/j.intcom.2012.04.009

*Balakrishnan, B., \& Sundar, S. S. (2011). Where am I? How can I get there? Impact of navigability and narrative transportation on spatial presence. Human-Computer Interaction, 26, 161-204. doi:10.1080/07370024.2011.601689

*Barendregt, W., Bekker, M. M., Bouwhuis, D. G., \& Baauw, E. (2006). Identifying usability and fun problems in a computer game during first use and after some practice. International Journal of Human-Computer Studies, 64, 830-846. doi:10.1016/j.ijhcs.2006.03.004

*Barr, P., Noble, J., \& Biddle, R. (2007). Video game values: Human-computer interaction and games. Interacting with Computers, 19, 180-195. doi:10.1016/j.intcom.2006.08.008 
Bavelier, D., Green, C. S., Pouget, A., \& Schrater, P. (2012). Brain plasticity through the life span: Learning to learn and action video games. Annual Review of Neuroscience, 35, 391-416. doi:10.1146/annurev-neuro-060909-152832

Bernhaupt, R. (2010). Evaluating user experience in games: Concepts and methods. London: Springer-Verlag.

*Bianchi-Berthouze, N. (2013). Understanding the role of body movement in player engagement. Human-Computer Interaction, 28, 40-75. doi:10.1080/07370024.2012.688468

*Billieux, J., Van der Linden, M., Achab, S., Khazaal, Y., Paraskevopoulos, L., Zullino, D., \& Thorens, G. (2013). Why do you play World of Warcraft? An in-depth exploration of selfreported motivations to play online and in-game behaviours in the virtual world of Azeroth. Computers in Human Behavior, 29, 103-109. doi:10.1016/j.chb.2012.07.021

Boyle, E. A., Connolly, T. M., Hainey, T., \& Boyle, J. M. (2012). Engagement in digital entertainment games: A systematic review. Computers in Human Behavior, 28, 771-780. doi:10.1016/j.chb.2011.11.020

Boyle, E., Kennedy, A.-M., Traynor, O., \& Hill, A. D. K. (2011). Training surgical skills using nonsurgical tasks - Can Nintendo Wii improve surgical performance? Journal of Surgical Education, 68, 148-154. doi:10.1016/j.jsurg.2010.11.005

*Bracken, C. C., \& Skalski, P. (2009). Telepresence and video games: The impact of image quality. PsychNology Journal, 7, 101-112. 
*Cairns, P., Cox, A. L., Day, M., Martin, H., \& Perryman, T. (2013). Who but not where: The effect of social play on immersion in digital games. International Journal of Human-Computer Studies, 71, 1069-1077. doi:10.1016/j.ijhcs.2013.08.015

Caroux, L., \& Isbister, K. (2014). Measuring aspects of player experience : A systematic review of human-computer interaction journals. Presented at the ACM CHI Conference on Human Factors in Computing Systems CHI'2014, Games User Research Workshop, Toronto, Canada. Retrieved from http://hcigames.businessandit.uoit.ca/chigur/wpcontent/uploads/2013/11/chigur2014_submission_3.pdf

*Caroux, L., Le Bigot, L., \& Vibert, N. (2011). Maximizing players' anticipation by applying the proximity-compatibility principle to the design of video games. Human Factors, 53, 103117. doi:10.1177/0018720811400600

*Caroux, L., Le Bigot, L., \& Vibert, N. (2013). Impact of the motion and visual complexity of the background on players' performance in video game-like displays. Ergonomics, 56, 18631876. doi:10.1080/00140139.2013.847214

*Chanel, G., Kivikangas, J. M., \& Ravaja, N. (2012). Physiological compliance for social gaming analysis: Cooperative versus competitive play. Interacting with Computers, 24, 306-316. doi:10.1016/j.intcom.2012.04.012

*Charlton, J. P., \& Danforth, I. D. W. (2007). Distinguishing addiction and high engagement in the context of online game playing. Computers in Human Behavior, 23, 1531-1548. doi:10.1016/j.chb.2005.07.002 
*Charlton, J. P., \& Danforth, I. D. W. (2010). Validating the distinction between computer addiction and engagement: online game playing and personality. Behaviour \& Information Technology, 29, 601-613. doi:10.1080/01449290903401978

*Choi, B., Huang, J., Jeffrey, A., \& Baek, Y. (2013). Development of a scale for fantasy state in digital games. Computers in Human Behavior, 29, 1980-1986. doi:10.1016/j.chb.2013.04.007

Christou, G., Lai-Chong Law, E., Zaphiris, P., \& Ang, C. S. (2013). Challenges of designing for sociability to enhance player experience in Massively Multi-player Online Role-playing Games. Behaviour \& Information Technology, 32, 724-734. doi:10.1080/0144929X.2012.754497

*Chung, J., \& Gardner, H. J. (2012). Temporal Presence Variation in Immersive Computer Games. International Journal of Human-Computer Interaction, 28, 511-529. doi:10.1080/10447318.2011.627298

*Claypool, K. T., \& Claypool, M. (2007). On frame rate and player performance in first person shooter games. Multimedia Systems, 13, 3-17. doi:10.1007/s00530-007-0081-1

Connolly, T. M., Boyle, E. A., MacArthur, E., Hainey, T., \& Boyle, J. M. (2012). A systematic literature review of empirical evidence on computer games and serious games. Computers \& Education, 59, 661-686. doi:10.1016/j.compedu.2012.03.004

Csikszentmihalyi, M. (1990). Flow: The psychology of optimal experience. New York: Harper and Row. 
Csikszentmihalyi, M. (1993). The evolving self: a psychology for the third millennium (1st ed.). New York, NY: HarperCollins Publishers.

De Kort, Y. A. W., \& ljsselsteijn, W. A. (2008). People, places, and play: Player experience in a socio-spatial context. ACM Computers in Entertainment, 6, article 18, 1-11. doi:10.1145/1371216.1371221

Derboven, J., Van Gils, M., \& De Grooff, D. (2011). Designing for collaboration: a study in intergenerational social game design. Universal Access in the Information Society, 11, 5765. doi:10.1007/s10209-011-0233-0

*De Simone, J. J., Verbruggen, T., Kuo, L.-H., \& Mutlu, B. (2012). Is cheating a human function? The roles of presence, state hostility, and enjoyment in an unfair video game. Computers in Human Behavior, 28, 2351-2358. doi:10.1016/j.chb.2012.07.005

*Dorr, M., Pomarjanschi, L., \& Barth, E. (2009). Gaze beats mouse: A case study on a gazecontrolled breakout. PsychNology Journal, 7, 197-211.

Egenfeldt-Nielsen, S. (2006). Overview of research on the educational use of video games. Digital Kompetanse, 1, 184-213.

Entertainment Software Association. (2013). Essential facts about the computer and video game industry. Retrieved from http://www.theesa.com/facts/gameplayer.asp

*Fabricatore, C., Nussbaum, M., \& Rosas, R. (2002). Playability in action videogames: a qualitative design model. Human-Computer Interaction, 17, 311-368. doi:10.1207/S15327051HCI1704_1 
*Fang, X., Chan, S., Brzezinski, J., \& Nair, C. (2010). Development of an instrument to measure enjoyment of computer game play. International Journal of Human-Computer Interaction, 26, 868-886. doi:10.1080/10447318.2010.496337

*Fang, X., Zhang, J., \& Chan, S. S. (2013). Development of an Instrument for Studying Flow in Computer Game Play. International Journal of Human-Computer Interaction, 29, 456470. doi:10.1080/10447318.2012.715991

*Gao, Y., Bianchi-Berthouze, N., \& Meng, H. (2012). What does touch tell us about emotions in touchscreen-based gameplay? ACM Transactions on Computer-Human Interaction, 19, article 31, 1-30. doi:10.1145/2395131.2395138

*González Sánchez, J. L., Vela, F. L. G., Simarro, F. M., \& Padilla-Zea, N. (2012). Playability: analysing user experience in video games. Behaviour \& Information Technology, 31, 1033-1054. doi:10.1080/0144929X.2012.710648

Hassenzahl, M., Diefenbach, S., \& Göritz, A. (2010). Needs, affect, and interactive products Facets of user experience. Interacting with Computers, 22, 353-362. doi:10.1016/j.intcom.2010.04.002

Hassenzahl, M., \& Tractinsky, N. (2006). User experience - A research agenda. Behaviour \& Information Technology, 25, 91-97. doi:10.1080/01449290500330331

Hornbæk, K. (2006). Current practice in measuring usability: Challenges to usability studies and research. International Journal of Human-Computer Studies, 64, 79-102. doi:10.1016/j.ijhcs.2005.06.002 
*Hou, J., Nam, Y., Peng, W., \& Lee, K. M. (2012). Effects of screen size, viewing angle, and players' immersion tendencies on game experience. Computers in Human Behavior, 28, 617-623. doi:10.1016/j.chb.2011.11.007

*Höysniemi, J., Hämäläinen, P., \& Turkki, L. (2003). Using peer tutoring in evaluating the usability of a physically interactive computer game with children. Interacting with Computers, 15, 203-225. doi:10.1016/s0953-5438(03)00008-0

Interactive Software Federation of Europe. (2011). About ISFE. Retrieved from http://www.isfe.eu/about-isfe

Interactive Software Federation of Europe. (2012). Videogames in Europe: consumer study. Retrieved from http://www.isfe.eu/sites/isfe.eu/files/attachments/euro_summary__isfe_consumer_study.pdf

International Organization for Standardization. (1998). Ergonomic requirements for office work with visual display terminals (VDTs) -- Part 11: Guidance on usability (ISO 9241-11:1998).

International Organization for Standardization. (2010). Ergonomics of human-system interaction -- Part 210: Human-centred design for interactive systems (ISO 9241-210:2010).

Isbister, K., Höök, K., Laaksolahti, J., \& Sharp, M. (2007). The sensual evaluation instrument: Developing a trans-cultural self-report measure of affect. International Journal of Human-Computer Studies, 65, 315-328. doi:10.1016/j.ijhcs.2006.11.017

Isbister, K., Höök, K., Sharp, M., \& Laaksolahti, J. (2006). The sensual evaluation instrument: developing an affective evaluation tool. In CHI 2006 Proceedings (pp. 1163-1172). New 
York: ACM. doi:10.1145/1124772.1124946

Isbister, K., \& Schaffer, N. (2008). Game usability: Advice from the experts for advancing the player experience. San Francisco: Morgan Kaufmann Publishers.

*Jennett, C., Cox, A. L., Cairns, P., Dhoparee, S., Epps, A., Tijs, T., \& Walton, A. (2008). Measuring and defining the experience of immersion in games. International Journal of HumanComputer Studies, 66, 641-661. doi:10.1016/j.ijhcs.2008.04.004

*Johnson, D., \& Wiles, J. (2003). Effective affective user interface design in games. Ergonomics, 46, 1332-1345. doi:10.1080/00140130310001610865

*Kivikangas, J. M., \& Ravaja, N. (2013). Emotional responses to victory and defeat as a function of opponent. IEEE Transactions on Affective Computing, 4, 173-182. doi:10.1109/TAFFC.2013.12

*Kleinsmith, A., \& Gillies, M. (2013). Customizing by doing for responsive video game characters. International Journal of Human-Computer Studies, 71, 775-784. doi:10.1016/j.ijhcs.2013.03.005

*Koo, D.-M. (2009). The moderating role of locus of control on the links between experiential motives and intention to play online games. Computers in Human Behavior, 25, 466-474. doi:10.1016/j.chb.2008.10.010

Lee, K. M. (2004). Presence, explicated. Communication Theory, 14, 27-50. doi:10.1111/j.14682885.2004.tb00302.x 
*Lee, M.-C., \& Tsai, T.-R. (2010). What drives people to continue to play online games? An extension of technology model and theory of planned behavior. International Journal of Human-Computer Interaction, 26, 601-620. doi:10.1080/10447311003781318

*Lim, S., \& Reeves, B. (2010). Computer agents versus avatars: Responses to interactive game characters controlled by a computer or other player. International Journal of HumanComputer Studies, 68, 57-68. doi:10.1016/j.ijhcs.2009.09.008

*Lin, H.-H., Wang, Y.-S., \& Chou, C.-H. (2012). Hedonic and utilitarian motivations for physical game systems use behavior. International Journal of Human-Computer Interaction, 28, 445-455. doi:10.1080/10447318.2011.618097

*Lin, Y.-L., \& Lin, H.-W. (2011). A study on the goal value for massively multiplayer online roleplaying games players. Computers in Human Behavior, 27, 2153-2160. doi:10.1016/j.chb.2011.06.009

*Liu, C., Agrawal, P., Sarkar, N., \& Chen, S. (2009). Dynamic difficulty adjustment in computer games through real-time anxiety-based affective feedback. International Journal of Human-Computer Interaction, 25, 506-529. doi:10.1080/10447310902963944

*Maby, E., Perrin, M., Bertrand, O., Sanchez, G., \& Mattout, J. (2012). BCl could make old twoplayer games even more fun: A proof of concept with "Connect Four." Advances in Human-Computer Interaction, 2012, article ID 124728, 1-8. doi:10.1155/2012/124728

Malliet, S. (2006). An exploration of adolescents' perceptions of videogame realism. Learning, Media and Technology, 31, 377-394. doi:10.1080/17439880601021983 
Malone, T. W., \& Lepper, M. R. (1987). Making learning fun: A taxonomy of intrinsic motivations for learning. In R. E. Snow \& M. J. Farr (Eds.), Aptitude, learning, and instruction: III. Conative and affective process analysis (pp. 223-253). Hillsdale, NJ: Lawrence Erlbaum.

*Mandryk, R. L., \& Atkins, M. S. (2007). A fuzzy physiological approach for continuously modeling emotion during interaction with play technologies. International Journal of Human-Computer Studies, 65, 329-347. doi:10.1016/j.ijhcs.2006.11.011

*McCall, R., \& Braun, A.-K. (2008). Experiences of evaluating presence in augmented realities. PsychNology Journal, 6, 157-172.

*McGloin, R., Farrar, K. M., \& Krcmar, M. (2011). The impact of controller naturalness on spatial presence, gamer enjoyment, and perceived realism in a tennis simulation video game. Presence: Teleoperators and Virtual Environments, 20, 309-324. doi:10.1162/PRES_a_00053

Merhi, O., Faugloire, E., Flanagan, M., \& Stoffregen, T. A. (2007). Motion sickness, console video games, and head-mounted displays. Human Factors, 49, 920-934. doi:10.1518/001872007x230262

*Nacke, L. E., Grimshaw, M. N., \& Lindley, C. A. (2010). More than a feeling: Measurement of sonic user experience and psychophysiology in a first-person shooter game. Interacting with Computers, 22, 336-343. doi:10.1016/j.intcom.2010.04.005

Nielsen, J. (1993). Usability engineering. San Francisco: Morgan Kaufmann.

Pagulayan, R., Keeker, K., Fuller, T., Wixon, D., Romero, R., \& Gunn, D. (2012). User-Centered 
Design in Games. In J. Jacko (Ed.), Human-Computer Interaction Handbook (pp. 795822). Boca-Raton, FL: CRC Press.

*Paiva, A., Costa, M., Chaves, R., Piedade, M., Mourão, D., Sobral, D., ... Bullock, A. (2003). SenToy: an affective sympathetic interface. International Journal of Human-Computer Studies, 59, 227-235. doi:10.1016/S1071-5819(03)00048-X

*Parés, N., \& Altimira, D. (2013). Analyzing the adequacy of interaction paradigms in artificial reality experiences. Human-Computer Interaction, 28, 77-114. doi:10.1080/07370024.2012.688469

*Park, N., Lee, K. M., Jin, S.-A. A., \& Kang, S. (2010). Effects of pre-game stories on feelings of presence and evaluation of computer games. International Journal of Human-Computer Studies, 68, 822-833. doi:10.1016/j.ijhcs.2010.07.002

*Pavlas, D., Jentsch, F., Salas, E., Fiore, S. M., \& Sims, V. (2012). The play experience scale: Development and validation of a measure of play. Human Factors, 54, 214-225. doi:10.1177/0018720811434513

*Peng, W., \& Hsieh, G. (2012). The influence of competition, cooperation, and player relationship in a motor performance centered computer game. Computers in Human Behavior, 28, 2100-2106. doi:10.1016/j.chb.2012.06.014

*Procci, K., Singer, A. R., Levy, K. R., \& Bowers, C. (2012). Measuring the flow experience of gamers: An evaluation of the DFS-2. Computers in Human Behavior, 28, 2306-2312. doi:10.1016/j.chb.2012.06.039 
*Qin, H., Rau, P. L. P., \& Salvendy, G. (2009). Measuring player immersion in the computer game narrative. International Journal of Human-Computer Interaction, 25, 107-133. doi:10.1080/10447310802546732

*Qin, H., Rau, P. L. P., \& Salvendy, G. (2010). Effects of different scenarios of game difficulty on player immersion. Interacting with Computers, 22, 230-239. doi:10.1016/j.intcom.2009.12.004

*Raisamo, R., Patomäki, S., Hasu, M., \& Pasto, V. (2007). Design and evaluation of a tactile memory game for visually impaired children. Interacting with Computers, 19, 196-205. doi:10.1016/j.intcom.2006.08.011

*Ravaja, N., Saari, T., Turpeinen, M., Laarni, J., Salminen, M., \& Kivikangas, M. (2006). Spatial presence and emotions during video game playing: Does it matter with whom you play? Presence: Teleoperators and Virtual Environments, 15, 381-392. doi:10.1162/pres.15.4.381

${ }^{*}$ Retaux, X. (2003). Presence in the environment: Theories, methodologies and applications to video games. PsychNology Journal, 1, 283-309.

*Ribbens, W., \& Malliet, S. (2010). Perceived digital game realism: a quantitative exploration of its structure. Presence: Teleoperators and Virtual Environments, 19, 585-600. doi:10.1162/pres_a_00024

*Sabri, A. J., Ball, R. G., Fabian, A., Bhatia, S., \& North, C. (2007). High-resolution gaming: Interfaces, notifications, and the user experience. Interacting with Computers, 19, 151- 
166. doi:10.1016/j.intcom.2006.08.002

*San Agustin, J., Mateo, J. C., Hansen, J. P., \& Villanueva, A. (2009). Evaluation of the potential of gaze input for game interaction. PsychNology Journal, 7, 213-235.

Shackel, B. (2009). Usability - Context, framework, definition, design and evaluation. Interacting with Computers, 21, 339-346. doi:10.1016/j.intcom.2009.04.007

*Shafer, D. M. (2013). An integrative model of predictors of enjoyment in console versus mobile video games. PsychNology Journal, 11, 137-157.

*Shafer, D. M., Carbonara, C. P., \& Popova, L. (2011). Spatial presence and perceived reality as predictors of motion-based video game enjoyment. Presence: Teleoperators and Virtual Environments, 20(6), 591-619. doi:10.1162/PRES_a_00084

*Shahid, S., Krahmer, E., \& Swerts, M. (2012). Video-mediated and co-present gameplay: Effects of mutual gaze on game experience, expressiveness and perceived social presence. Interacting with Computers, 24, 292-305. doi:10.1016/j.intcom.2012.04.006

*Shaker, N., Asteriadis, S., Yannakakis, G. N., \& Karpouzis, K. (2013). Fusing visual and behavioral cues for modeling user experience in games. IEEE Transactions on Cybernetics, 43, 15191531. doi:10.1109/TCYB.2013.2271738

*Shin, D.-H., \& Shin, Y.-J. (2011). Why do people play social network games? Computers in Human Behavior, 27, 852-861. doi:10.1016/j.chb.2010.11.010

*Silva, J. M., \& El Saddik, A. (2013). Exertion interfaces for computer videogames using 
smartphones as input controllers. Multimedia Systems, 19, 289-302.

doi:10.1007/s00530-012-0268-y

*Skalski, P., \& Whitbred, R. (2010). Image versus sound: A comparison of formal feature effects on presence and video game enjoyment. PsychNology Journal, 8, 67-84.

*Song, H., Kim, J., Tenzek, K. E., \& Lee, K. M. (2013). The effects of competition and competitiveness upon intrinsic motivation in exergames. Computers in Human Behavior, 29, 1702-1708. doi:10.1016/j.chb.2013.01.042

Stanney, K. M., Mollaghasemi, M., Reeves, L., Breaux, R., \& Graeber, D. A. (2003). Usability engineering of virtual environments (VEs): Identifying multiple criteria that drive effective VE system design. International Journal of Human-Computer Studies, 58, 447481. doi:10.1016/s1071-5819(03)00015-6

Takatalo, J., Kawai, T., Kaistinen, J., Nyman, G., \& Hakkinen, J. (2011). User experience in 3D stereoscopic games. Media Psychology, 14, 387-414. doi:10.1080/15213269.2011.620538

*Teng, C.-I. (2010). Customization, immersion satisfaction, and online gamer loyalty. Computers in Human Behavior, 26, 1547-1554. doi:10.1016/j.chb.2010.05.029

Trepte, S., \& Reinecke, L. (2010). Avatar creation and video game enjoyment. Journal of Media Psychology: Theories, Methods, and Applications, 22, 171-184. doi:10.1027/1864$1105 / a 000022$

*Van de Laar, B., Bos, D. P.-O., Reuderink, B., Poel, M., \& Nijholt, A. (2013). How much control is 
enough? Influence of unreliable input on user experience. IEEE Transactions on Cybernetics, 43, 1584-1592. doi:10.1109/TCYB.2013.2282279

*Vickers, S., Istance, H., \& Hyrskykari, A. (2013). Performing locomotion tasks in immersive computer games with an adapted eye-tracking interface. ACM Transactions on Accessible Computing, 5, article 2, 1-33.

*Voiskounsky, A. E., Mitina, O. V., \& Avetisova, A. A. (2004). Playing online games: Flow experience. PsychNology Journal, 2, 259-281.

*Von der Pütten, A. M., Klatt, J., Ten Broeke, S., McCall, R., Krämer, N. C., Wetzel, R., ... Klatt, J. (2012). Subjective and behavioral presence measurement and interactivity in the collaborative augmented reality game TimeWarp. Interacting with Computers, 24, 317325. doi:10.1016/j.intcom.2012.03.004

Wang, C. K. J., Liu, W. C., \& Khoo, A. (2009). The psychometric properties of Dispositional Flow Scale-2 in internet gaming. Current Psychology, 28, 194-201. doi:10.1007/s12144-0099058-x

*Weibel, D., Wissmath, B., Habegger, S., Steiner, Y., \& Groner, R. (2008). Playing online games against computer- vs. human-controlled opponents: Effects on presence, flow, and enjoyment. Computers in Human Behavior, 24, 2274-2291. doi:10.1016/j.chb.2007.11.002

*Wolfson, S., \& Case, G. (2000). The effects of sound and colour on responses to a computer game. Interacting with Computers, 13, 183-192. doi:10.1016/S0953-5438(00)00037-0 
Yannakakis, G. N., \& Hallam, J. (2007). Towards optimizing entertainment in computer games. Applied Artificial Intelligence, 21, 933-971. doi:10.1080/08839510701527580

*Yannakakis, G. N., Martínez, H., \& Jhala, A. (2010). Towards affective camera control in games. User Modeling and User-Adapted Interaction, 20, 313-340. doi:10.1007/s11257-0109078-0

Zhu, M., \& Fang, X. (2014). Developing playability heuristics for computer games from online reviews. In A. Marcus (Ed.), Design, User Experience, and Usability. Theories, Methods, and Tools for Designing the User Experience (pp. 496-505). New York: Springer International Publishing. 


\section{TABLES}

Table 1. Game design recommendations, based on results reported in the present review in two or more experiments, that game designers should follow to create better player-video game interactions.

$\begin{array}{ll}\text { Design recommendation } & \text { Basis article }\end{array}$

\section{Visual output}

Image quality, in terms of resolution and frame rate, should be the highest possible

Bracken \& Skalski, 2009; Claypool

\& Claypool, 2007

Main elements of contextual information should be located close to current action or anticipation zones, but should not overlap with them

Caroux et al., 2011; Sabri el al. 2007

\section{Input technique}

For motion-based games, the controller should allow the most natural and precise gesture possible

McGloin et al., 2011; Shafer et al., 2011

\section{Game challenge}

Dynamic difficulty should be based on players' emotions (rather than their actual performance)

Liu et al., 2009; Shaker et al., 2013

\section{Game narrative}

A narrative context should be introduced at the beginning of the game

Park et al., 2010

\section{Online multiplayer games}

The game should introduce the game partner (ally or enemy) as a human player rather than the computer, even if it is not true

Real-time video chat should be displayed when friends play together

Cairns et al., 2013; Lim \& Reeves, 2010 ; Ravaja et al., 2006 ; Weibel et al., 2008

Derboven et al., 2011 ; Shahid et al., 2012 
Table 2. Number of articles focusing of each player aspect of player-video game interaction by method used or proposed.

\begin{tabular}{|c|c|c|c|c|c|c|c|c|}
\hline \multirow[b]{2}{*}{ Player aspect } & \multicolumn{2}{|c|}{ Subjective measures } & \multicolumn{6}{|c|}{ Objective measures } \\
\hline & Questionnaire & Interview & $\begin{array}{l}\text { Physiological } \\
\text { measure }\end{array}$ & Eye-tracking & $\begin{array}{l}\text { Finger stroke } \\
\text { behavior }\end{array}$ & $\begin{array}{l}\text { Non-verbal } \\
\text { cues }\end{array}$ & $\begin{array}{l}\text { Post-task } \\
\text { performance }\end{array}$ & User testing \\
\hline Engagement & 4 & 1 & & & & 1 & & \\
\hline Presence & 18 & 1 & & & & 1 & & \\
\hline Enjoyment & 15 & & & & & & & \\
\hline Flow & 5 & 1 & & & & & & \\
\hline
\end{tabular}

Note. One article can be counted several times if more than one method or more than one player aspect is studied. 


\section{FIGURE}

Figure 1. Aspects of player-video game interactions, and their related concepts, studied in the literature review. Each aspect (colored frames) is presented in a specific sub-section of the results section. Their related concepts (black frames) are detailed in each of these sub-sections.

Player aspects

Video game aspects

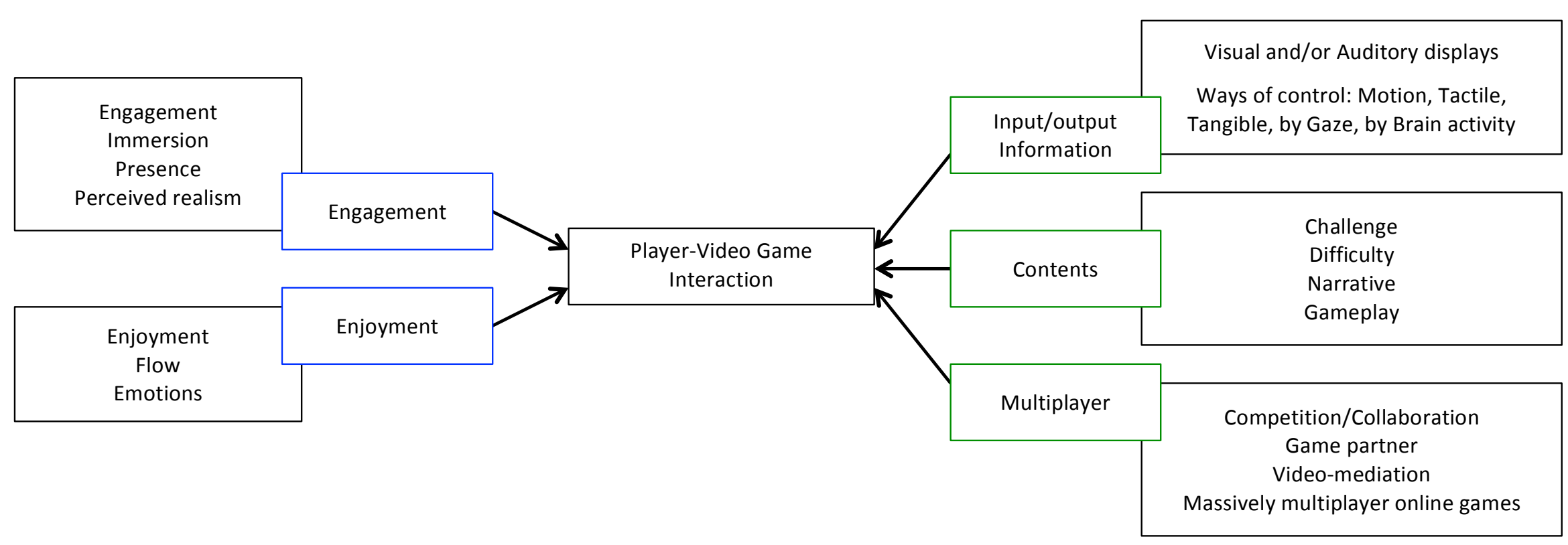

